\title{
Infrared Emission Spectrum of Methane at 3.3 Microns
}

\author{
Earle K. Plyler and Lamdin R. Blaine
}

\begin{abstract}
The emission spectrum of methane from the flame of a Bunsen burner has been observed in the region from 2,820 to $3,180 \mathrm{~cm}^{-1}$. Many lines have been measured in the $P$-, $Q$-, and $R$-branches. The $P$-branch was observed to $P-28$ and the $R$-branch to $R-17$.

The spectrum was observed from the inner cone of the flame and with a rich fuel mixture the $P-12$ line was most intense. This intensity distribution indicated a temperature of about $1,200^{\circ} \mathrm{K}$ for the heated gas.
\end{abstract}

\section{Introduction}

In the measurement of the emission spectrum from a flame [1] ${ }^{2}$ with methane gas as a fuel, it was shown that the bands of greatest intensity were produced by the molecules of $\mathrm{H}_{2} \mathrm{O}$ and $\mathrm{CO}_{2}$ at elevated tem-peratures. In further studies it was shown [2] that weak bands are produced in the infrared spectra of flames from the molecules of $\mathrm{OH}, \mathrm{CO}$, and $\mathrm{C}_{2}$. A weak emission band was observed also in the region of $3.3 \mu$ from the inner cone of a methane-oxygen flame. This band was identified as arising from the heated methane molecules before combustion took place. No rotational structure was observed in the band, but the position and type of band observed made it highly probable that it was an emission band of methane. The present work was undertaken to ascertain if the spectrum. when measured under high resolution contained a rotational structure which was similar to that of methane. Also from the spectrum under high resolution it would be possible to determine the temperature of the heated gas.

\section{Experimental Method}

The spectra were measured by the use of a grating spectrometer having a grating of 10,000 lines per inch. Other details concerning the spectrometer have been given in a previous publication [3].

Under the most suitable conditions a resolution of $0.05 \mathrm{~cm}^{-1}$ is obtained in the region of $3.3 \mu$, but on account of the low intensity of the emission of the flame, it was necessary to widen the slits so that the resolution obtained in this work is about $0.10 \mathrm{~cm}^{-1}$. Two types of burners were used for obtaining the methane spectrum. The first type was a glassblower's torch where mixtures of methane and oxygen were burned. The intensity was then compared with that obtained from a flame of a Bunsen burner in which a mixture of methane and air was used. It was found that the radiation from the inner cone of the flame of a Bunsen burner was more intense in the region of the methane band, and it was used for measuring the spectrum. The flame was low in intensity and a group of mirrors was used to increase the available energy on the entrance slit of the spec-

1 This work was supported in part by the Geophysics Research Directorate, Air Force Cambridge Research Center.

${ }_{2}^{2}$ Figures in brackets indicate the literature references at the end of this paper trometer [4]. In the use of the optical system., part of the radiation is focused back on the flame. The flame absorbs some of the reflected energy, but the amount is small. It was found that the strongest lines showed an increase in the energy on the entrance slit by a factor of 3.5. This factor of increased energy approaches the value of 4 , which would be the gain in energy if there were no absorption in the flame and no reflection losses from the mirrors.

In observing the spectrum in the $3.3-\mu$ region a rich fuel mixture was used for the flame. The Bunsen burner was adjusted so that an inner cone 4 in. in height was obtained, and a section of the inner cone about $3 \mathrm{in}$. above the top of the burner was focused on the entrance slit of the spectrometer.

\section{Results}

The observed spectrum from 2,820 to $3,180 \mathrm{~cm}^{-1}$ is shown in figure 1 . The $P_{-}, Q_{-}$, and $R$-branches of the $1 \rightarrow 0$ transition of methane stand out clearly, but there are present a number of lines that are not a part of the transition producing this band. Some of the extra lines are part of the emission spectrum. of $\mathrm{H}_{2} \mathrm{O}$. The emission spectrum of water became so intense at $3,180 \mathrm{~cm}^{-1}$ and at higher frequencies that the methane lines beyond $R-18$ could not be identified. In addition to the water vapor spectrum, many small lines between the main series in the $P$-branch arise from hot bands, but they were not classified and no other bands except the $1 \rightarrow 0$ transition were identified. On increasing the slit width a large number of lines became sufficiently intense for detection and the band extended to longer wavelengths. However, measurements were made on the positions of the lines with a narrow slit and under these conditions the main lines of the $P$ - and $R$ branches were overlapped only slightly.

In several scannings of the spectrum the $P-12$ line was the most intense. Calculation shows that this intensity distribution of the rotational lines leads to a temperature of about $1,200^{\circ} \mathrm{K}$ for the heated gas. This is an average across the inner cone. The molecules on the outer periphery of the inner cone, close to the burning gas, are probably at a somewhat higher temperature and those at the center of the cone may be cooler than $1,200^{\circ} \mathrm{K}$.

The present study shows that a molecule used as a fuel for combustion may radiate its own characteristic spectra if it is sufficiently heated before combus- 


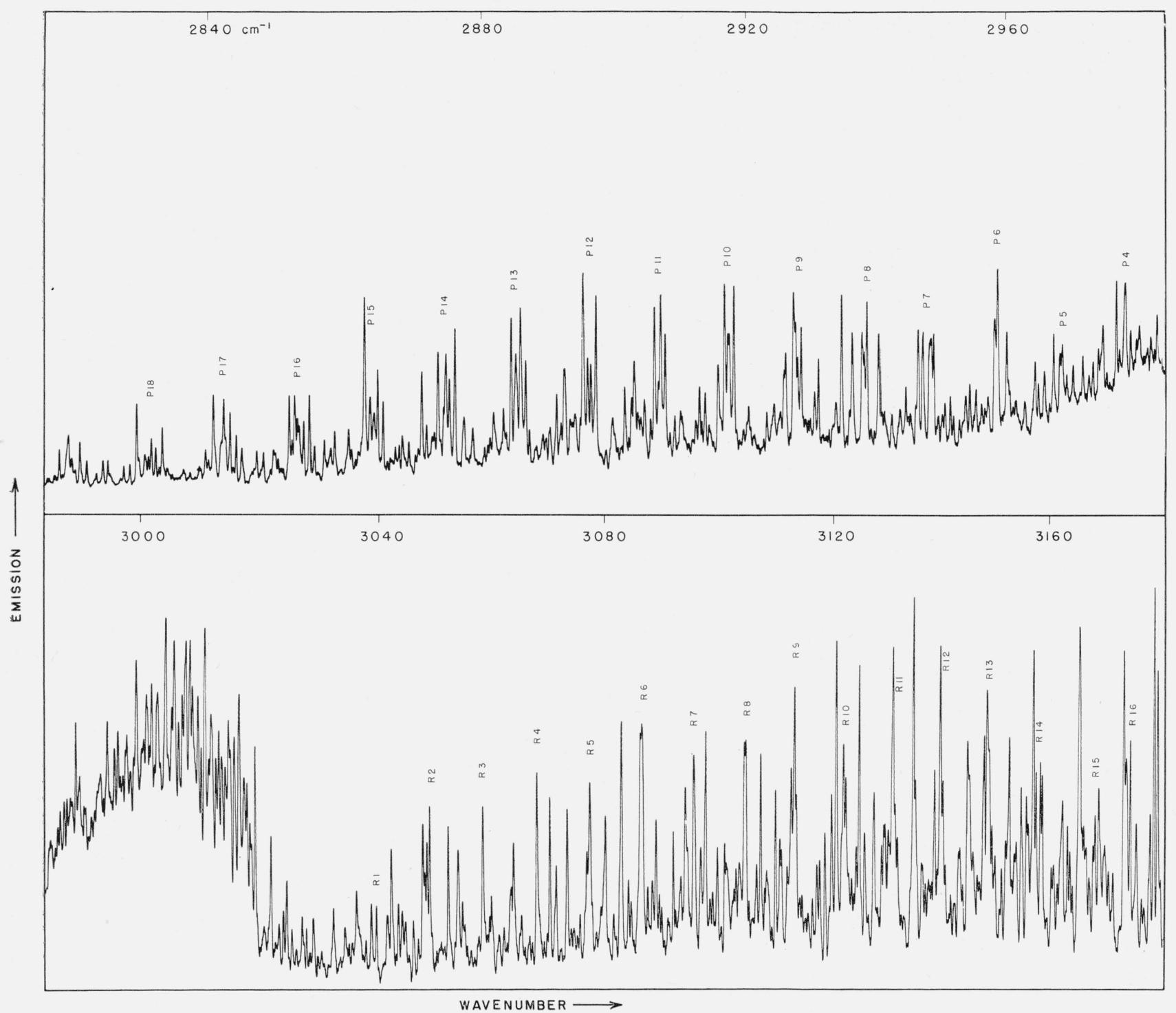

FIGURE 1. Emission spectrum of methane from 2,820 to $3,180 \mathrm{~cm}^{-1}$.

The spectrum was observed from a methane-air flame with a rich fuel mixture.

tion. This is a useful method of measuring the spectra of some gases at elevated temperatures. The emission spectrum is more complex than the spectrum observed in absorption because the elevated temperature increases the intensity of some rotational transitions with low probability. The additional lines in emission arise from the transitions of high quantum numbers and are useful in obtaining a better description of the energy states of the molecule.

Another method for the study of the emission spectra of molecules has been worked out by Wilkinson, Ford, and Price [5]. The infrared emission of gases is obtained by a radiofrequency discharge, which produces bands of the ground state and of the higher states. This method of excitation has some advantages over the flame for the study of emission spectra, especially since molecules can be measured without the overlapping of other spectra such as those of water vapor and carbon dioxide.

\section{References}

[1] Earle K. Plyler and Curtis J. Humphreys, J. Research NBS 40, 449 (1948) RP'1890.

[2] Earle K. Plyler and J. J. Ball, J. Chem. Phys. 20, 1178 (1952); Earle K. Plyler, Mikrochimica Acta 2-3, 421428 (1955).

[3] Earle K. Plyler, Lamdin R. Blaine, and Eugene D. Tidwell, J. Research NBS 55, 279 (1955) RP2630.

[4] Earle K. Plyler and Henry J. Kostkowski, J. Opt. Soc. Am. 4\%, 360 (1952).

[5] G. R. Wilkinson, M. A. Ford, and W. C. Price, Molecular Spectroscopy, The Institute of Petroleum, London (1955).

Washington, April 17, 1957. 